requiring our closest concern, and among other professional researchers (e.g. sociologists, anthropologists) with whom we have traditionally cooperated. Careful social and community research must now be the real priority in the issue of schizophrenia and Afro-Caribbeans.

GLOVER, G. R. (1989) Why is there a high rate of schizophrenia in British Caribbeans? British Journal of Hospital Medicine, 42, 48-51.

O'Callaghan, E., Sham, P., Take, N., et al (1991) Schizophrenia after prenatal exposure to 1957 A2 influenza epidemic. Lancet, $337,1248-1250$.

St Bartholomew's and Homerton Hospitals

T. H. TURNER

Homerton Row

London E9 6SR

SIR: We read with interest the papers by Castle et al (Journal, December 1991, 159, 790-794) and Wessely et al (Journal, December 1991, 159, 795-801) and note their finding of higher rates of operationally defined schizophrenia among Afro-Caribbeans in the UK. In discussing possible explanations for these findings, Dr Wessely et al suggested that the prevalence of schizophrenia in this group could be increased either directly or indirectly by forms of social adversity such as unemployment, inadequate housing, low social class, the experience of racism and other forms of social deprivation.

The puzzling thing about these hypotheses to account for the higher rates of major mental illness is that the same factors are associated with an increased risk of non-psychotic disorders such as depression, anxiety, and functional somatic symptoms (Goldberg \& Huxley, 1992). Yet the British evidence is that AfroCaribbean patients are less likely to receive this diagnosis from general practitioners (GPs) than white British attenders. Gillam et al (1989), reviewing over 67000 GP consultations in Brent, North London, found that GPs were less likely to diagnose psychosocial disorders in Afro-Caribbean attenders than in white British attenders. Similarly Johnson et al (1986) found from a community survey in the West Midlands that Afro-Caribbean respondents were much less likely than white British respondents to report having attended their GP with a psychological problem.

There are several possible interpretations of these apparently contradictory findings concerning schizophrenia and non-psychotic disorders. Firstly, the excess of schizophrenia might be due to biological not social factors, a consideration raised by Dr Wessely et al. Secondly, the excess of schizophrenia could be due to misdiagnosis, although the weight of evidence against this is increasing. Thirdly, the theories about the social precursors of schizophrenia might be correct yet operate differently with regard to nonpsychotic disorders resulting in differing rates in the Afro-Caribbean population. Fourthly, AfroCaribbean patients with non-psychotic disorders might not attend their GPs or the GP might not recognise these disorders. This could be due either to the mode of symptom presentation, or cultural differences in the nature of non-psychotic disorders (Helman, 1990). Lastly, it could be that AfroCaribbean patients do not frame their distress in psychological terms because of the tremendous stigma attached to mental illness and the black community's discriminatory experiences of the mental health care system (Rack, 1982). Another aspect of discrimination which might impact upon the presentation and recognition of non-psychotic disorders is differential access to services and the unacceptability of having the stresses of living with discrimination redefined as neurotic illness (Rack, 1982).

Compared to the volume of work conducted into schizophrenia and the Afro-Caribbean community, relatively little work has been carried out in the UK on non-psychotic disorders such as anxiety, depression and somatic symptoms. If theories about the direct and indirect roles of social adversity in schizophrenia among Afro-Caribbeans in the UK are correct, then some explanation is required as to why it has been suggested that rates of non-psychotic disorders in primary care settings are lower, the opposite of what might be expected from work on vulnerability factors to non-psychotic disorders among the general population.

Gillam, S., Jarman, B., White, P., et al (1989) Ethnic differences in consultation rates in urban general practice. British Medical Journal, 299, 953-958.

GoldberG, G. \& HuXley, P. (1992) Common Mental Disorders: A Bio-social Model. London: Routledge.

Helman, C. G. (1990) Culture, Health \& Illness. 2nd edn. Bristol: Wright.

JoHnson, M. (1986) Inner city residents, ethnic minorities and primary health care in the West Midlands. In Health, Race \& Ethnicity (eds T. Rathwell \& D. Phillips). Kent: Croom Helm.

RACK, P. (1982) Race, Culture \& Mental Disorder. London: Tavistock.

Institute of Psychiatry

KEITH LLOYD

LYNN ST LouIS

Section of Epidemiology \& General Practice

De Crespigny Park

London SE5 8AF

SIR: Dr Eagles focuses interest on biological factors as possible causes of the excess of schizophrenia 
among British Afro-Caribbeans (Journal, December 1991, 159, 783-789). He omits to suggest a role for cannabis use, for which there is some evidence. Cannabis use among psychotic Afro-Caribbeans in Nottingham was much higher than among white patients (Harrison et al, 1989). Frequent use among young men is followed by a six-fold increase in admissions for schizophrenia (Andreasson et al, 1987). Interestingly, sharp excesses are seen for schizophrenia in young Afro-Caribbean men in the UK (Glover, 1989) and in Jamaica (Burke, 1974).

Data from a follow-up study I have completed (Sugarman, 1992) produced two incidental findings. A history of cannabis use had been recorded in the case notes significantly more often for UK-born young black men with schizophrenia than for matched white patients $(P<0.005)$. While age, age of onset, length of illness, sex, family history, and presence of first-rank symptoms did not predict outcome, Afro-Caribbeans noted to take cannabis had a better total outcome score than other AfroCaribbeans $(P<0.05)$. Stepwise multiple regression did not suggest that this was attributable to the age and sex distribution of cannabis use.

It may be, therefore, that there is a subpopulation of Afro-Caribbean schizophrenics, mainly young men, with a good prognosis illness precipitated by cannabis. Such cases may be part of the explanation for high rates of illness in this ethnic group.

Andreasson, S., Allebeck, P., Engstroem, A., et al (1987) Cannabis and schizophrenia. A longitudinal study of Swedish conscripts. Lancet, ii, 1483-1486.

BURKE, A. W. (1974) First admissions and planning in Jamaica Social Psychiatry. 9, 39-45.

GlOVER, G. (1989) The pattern of psychiatric admissions of Caribbean-born immigrants in London. Social Psychiatry and Psychiatric Epidemiology, 24, 49-56.

Harrison, G., Holton, A., Neilson, D., el al (1989) Severe mental disorder in Afro-Caribbean patients: some social, demographic and service factors. Psychological Medicine, 19, 683-696.

Sugarman, P. A. (1992) Outcome of schizophrenia in the AfroCaribbean community. Social Psychiatry and Psychiatric Epidemiology (in press)

Reaside Clinic

P. A. Sugarman

Bristol Road South

Rubery

Rednal

Birmingham B45 9BE

\section{Anorexia nervosa and XY gonadal dysgenesis}

SIR: I read with great interest the report by McCluskey \& Lacey (Journal, January 1992, 160, 114-116) which demonstrated how anorexic psychopathology might result from $X Y$ gonadal dysgenesis, its adverse psychosocial effects and medical treatment. While I do not debate that the patient exhibited low selfesteem, psychosexual identity problems, and family conflicts, as well as certain clinical features which may be found in female patients with anorexia nervosa, and was likely to benefit from psychological help, the case raises interesting questions about the diagnosis of anorexia nervosa in subjects with XY gonadal dysgenesis which the authors did not discuss. They mentioned that the patient fulfilled the DSMIII-R criteria for anorexia nervosa which essentially required: (a) weight loss of $15 \%$ from standard body weight; (b) amenorrhoea; (c) an intense fear of obesity or body-image distortion.

One problem in diagnosis may arise because subjects with $\mathrm{XY}$ gonadal dysgenesis, as the authors indicated, are tall and with a eunuchoid habitus. Unlike the much more frequently reported association of anorexia nervosa with Turner syndrome in which affected subjects are typically short, this body build will naturally lead to a low body mass index (BMI) to start with. Hence, it is doubtful whether one can estimate weight loss for these subjects by making reference to standard weight charts of normal females. Surprisingly, the authors did not mention the original body weight or BMI of the patient before oestrogen therapy. Nonetheless, even when she was happiest during her 'only sexual relationship', she was noted to weigh only $47 \mathrm{~kg}$ at a height of $1.74 \mathrm{~m}$. This gives a BMI of only $15.5 \mathrm{~kg} / \mathrm{m}^{2}$ which, according to the ICD-10 proposed criteria (specifically $B M I \leqslant 16 \mathrm{~kg} / \mathrm{m}^{2}$ ) for the diagnosis of anorexia nervosa (World Health Organization, 1987), is still in the anorexic range. It is therefore possible that the patient could have had an 'anorexic body shape' even before the development of her psychopathology. If this premorbid body weight was used as reference, the patient would have a weight loss of only $12.8 \%(6 \mathrm{~kg})$ which was below the DSM-III-R requirement. Thus, the patient might fulfil DSM-III-R criteria only if her body weight achieved with oestrogen therapy was used as her 'original' body weight in the estimation of weight loss. However, this medically induced 'normal' body weight, which she seemed ill prepared for, was paradoxically a contributory factor to her eating disorder, as the authors pointed out.

The above diagnostic problem is compounded by two other issues. Firstly, as subjects with XY gonadal dysgenesis by their very nature suffer from primary amenorrhoea, this diagnostic criterion, being automatically fulfilled, will become less useful clinically. Thus, I have encountered Hong Kong Chinese girls (including two medical students recently) who have a BMI of $16 \mathrm{~kg} / \mathrm{m}^{2}$ and a certain fear of obesity, but 